\title{
El avance del COVID-19 en Santiago de Chile y su relación con las vulnerabilidades socio-ambientales urbanas
}

\author{
The advance of COVID-19 in Santiago de Chile and its relationship with \\ urban socio-environmental vulnerabilities
}

\section{O avanço da COVID-19 em Santiago do Chile e sua relação com as vulnerabilidades socioambientais urbanas}

\author{
Hugo Romero y y Flávio Henrique Mendes ${ }^{2}$
}

\author{
${ }^{1}$ Facultad de Arquitectura y Urbanismo (FAU), Universidad de Chile (UChile) \\ hromero@uchilefau.cl - https://orcid.org/0000-0002-1005-0269 \\ 2 Escola Superior de Agricultura “Luiz de Queiroz" (ESALQ), Universidade de São Paulo (USP) \\ friquemendes@usp.br - https://orcid.org/0000-0002-7628-4850
}

\begin{abstract}
RESUMEN
La pandemia del COVID-19 obligó a los gobiernos nacionales a emprender acciones de aislamiento social, con el objetivo de frenar el avance del virus y sus brutales efectos sobre la salud y bienestar de la población. Este trabajo pretende analizar el comportamiento de este avance en Santiago de Chile, la capital del país ubicada en la llamada Región Metropolitana, que tiene más de siete millones de habitantes distribuidos en 38 comunas o municipios. Por medio de imágenes térmicas satelitales Landsat-7 es posible caracterizar las áreas más vegetadas de la ciudad, que se correlacionan espacialmente con los sectores de menor variación térmica y donde residen los grupos sociales de mayores ingresos económicos. Se cruzaron los valores de las temperaturas superficiales y las tasas de incidencia de la pandemia en cada comuna, para los meses de abril, mayo y julio de 2020. Los contagios surgieron en el mes de abril, a comienzos del otoño, en las comunas más ricas de la ciudad, ubicadas en el sector oriente, tales como Vitacura, Las Condes, Lo Barnechea y Providencia. Al mes siguiente, se extendieron en forma homogénea por toda la ciudad, y en el mes de julio, en el corazón de la estación de invierno, localizarse preferentemente en las comunas más pobres que alcanzaron las mayores tasas de incidencia, como La Granja, La Pintana, San Ramón, Renca y San Joaquín, con al menos 4500 contagios cada 100 mil hab., que corresponde a 4,5\% de sus poblaciones actuales. Persisten muchas incertidumbres sobre el comportamiento espacial del COVID-19 y sus factores causales, entre ellos el ambiente natural, representado por el clima urbano, y los determinantes socio-económicos de una ciudad caracterizada por profundas desigualdades socio-económicas y socio-ambientales.
\end{abstract}

\section{ABSTRACT}

The COVID-19 pandemic forced national governments to take social isolation actions, with the aim of stemming the progress of the virus and its brutal effects on the health and well-being of the population. This work aims to analyze the spatial behavior of this development in Santiago de Chile, 
the capital of the country located in the so-called Metropolitan Region, which has more than seven million inhabitants distributed in 38 communes or municipalities. By means of Landsat-7 satellite thermal images it is possible to characterize the most vegetated areas of the city, which are spatially correlated with those with lower thermal variation and the location of upper socioeconomic groups. The surface temperature values and pandemic incidence rates were crossed in each commune for the months of April, May and July 2020. The results showed that the rates of contagion arose in the richest communes of the city, located in the eastern side, such as Vitacura, Las Condes, Lo Barnechea and Providencia, in the month of April, in the beginning of the autumn. In the following month, it spreads evenly throughout the city, and in July, under the heart of the winter season, preferably locate itself in the poorest communes that reach the highest incidence rates, such as La Granja, La Pintana, San Ramón, Renca and San Joaquín, with at least 4500 contagions every 100 thousand people, which corresponds to $4.5 \%$ of its current populations. Many uncertainties persist about the spatial behavior of COVID-19 and its causes such as the natural environment, represented by the urban climate, and the socio-economic determinants of a city clearly characterized by deep socio-economic and socioenvironmental inequalities.

\section{RESUMO}

A pandemia da COVID-19 obrigou os governos nacionais a realizar ações de isolamento social, com o objetivo de conter a propagação do vírus e seus efeitos brutais na saúde e no bem-estar da população. Este trabalho tem como objetivo analisar o comportamento desse avanço em Santiago do Chile, capital do país localizada na chamada Região Metropolitana, que possui mais de sete milhões de habitantes distribuídos em 38 comunas ou municípios. Por meio de imagens térmicas do satélite Landsat-7 é possível caracterizar as áreas mais vegetadas da cidade, que estão espacialmente correlacionadas com os setores de menor variação térmica e onde residem os grupos sociais de maior renda econômica. Foram cruzados os valores das temperaturas superficiais e as taxas de incidência da pandemia em cada comuna, para os meses de abril, maio e julho de 2020. As infecções surgiram no mês de abril, no início do outono, nas comunas mais ricas da cidade, localizadas no setor oriente, como Vitacura, Las Condes, Lo Barnechea e Providencia. No mês seguinte, espalharam-se de forma homogênea pela cidade, y em julho, no auge do inverno, preferencialmente as comunas mais pobres e alcançaram as maiores taxas de incidência, como La Granja, La Pintana, San Ramón, Renca e San Joaquín, com pelo menos 4.500 infecções por 100.000 habitantes, o que corresponde a $4,5 \%$ de suas populações atuais. Muitas incertezas persistem sobre o comportamento espacial da COVID-19 e seus fatores causais, incluindo o ambiente natural, representado pelo clima urbano, e os determinantes socioeconômicos de uma cidade caracterizada por profundas desigualdades socioeconômicas e socioambientais.

PALABRAS-CLAVE: Coronavirus; temperatura superficial; tasa de incidencia.

KEYWORDS: Coronavirus; surface temperature; incidence rate.

PALAVRAS-CHAVE: Coronavírus; temperatura de superfície; taxa de incidencia.

\section{Introducción}

El 11 de marzo de 2020 la Organización Mundial de la Salud (OMS) decretó pandemia por el COVID-19. Cinco meses después, el 14 de agosto de 2020, el mundo registraba 21 millones de contagiados, destacando las mayores cifras de Estados Unidos (5 millones), Brasil (3 millones) e India (2,5 millones), países muy populosos. De los 21 millones contagiados a dicha fecha, habían ocurrido 760 mil muertes, lo que representa una letalidad de $3,6 \%$ a escala global. Chile ocupaba el $9^{\circ}$ puesto entre los países con mayor número de infectados, con 380 mil casos y 10,3 mil muertes, presentando una letalidad de 2,7\%. En la Región Metropolitana de Santiago (RMS) se concentraba el $70 \%$ de las personas contagiadas y la letalidad mayor del país, de 3,0\% (JHU, 2020).

El objetivo de esta investigación ha sido analizar preliminarmente el comportamiento espacial del avance del COVID-19 en Santiago de Chile, relacionando su trayectoria, los datos actuales y las tendencias, con factores causales naturales y socio-económicos.

Investigaciones realizadas en los diversos países han correlacionado el aparecimiento de la pandemia y la distribución espacial de sus contagios con el clima de las regiones 
afectadas (Gutiérrez-Hernández \& García, 2020; Ma et al., 2020; Sajadi et al., 2020). Los resultados concluyen que en la mayoría de las regiones de climas subtropicales y de tipo mediterráneo alcanzaron su máxima difusión en los meses más fríos y secos, pero en las regiones tropicales esto ocurrió bajo condiciones cálidas y húmedas. En Chile, país largo que cruza zonas subtropicales, mediterráneas y templadas, las máximas tasas de contagio han variado durante los últimos meses entre sus regiones del norte, centro y sur del país (JHU, 2020), demostrando con ello que la correlación con los climas debe ser complementada en todos los casos con los determinantes socioeconómicos que en el caso de las ciudades, presentan igualmente grandes variaciones socio-espaciales.

Sin embargo, en las relaciones estadísticas entre climas y pandemia no se ha prestado mayor atención a las asociaciones espaciales entre los climas urbanos y el comportamiento del virus. Como es sabido, al interior de las ciudades, las condiciones de temperatura, humedad y ventilación, varían significativamente en función de los usos y coberturas de los suelos, densidad y elevación de las construcciones y extensión y cobertura de las áreas verdes. Como estos atributos se relacionan a su vez, en las ciudades latinoamericanas, con los niveles socio-económicos de sus habitantes, los climas urbanos deben ser comprendidos también como indicadores de la segregación socio-espacial e injusticia ambiental existente en Santiago como en toda la región. Bajo los principios neoliberales que han significado la privatización y comodificación de los bienes y servicios ambientales urbanos, se puede acceder a las mejores y más seguras condiciones climáticas y de calidad del aire solo si se poseen los recursos económicos suficientes para residir en los sectores que registran estos atributos. La mayoría de los habitantes de ciudades como Santiago lo hacen en áreas de riesgos como inundaciones, remoción en masa, ocurrencia de olas de frío y calor, temperaturas extremas, ausencias de vegetación, menor humedad atmosférica y reducida ventilación y por ello, elevadas concentraciones de contaminantes atmosféricos. Los climas urbanos y el aire de buena calidad no corresponden a bienes libres y comunes en la mayoría de las ciudades latinoamericanas y los estudios de climatología geográfica deben contribuir a resolver esta injusticia socio-ambiental y proponer la re-comunalización de los climas como un servicio ambiental indispensable para la salud y bienestar de la población (Romero, 2019). La climatología urbana debe formar parte de la planificación de las ciudades para combatir el Cambio Climático, controlar las pandemias y ofertar mayor seguridad y calidad de vida a sus habitantes.

\section{Materiales y Métodos}

El área de estudio ha sido la ciudad de Santiago, localizada en las coordenadas geográficas $33^{\circ} 26^{\prime} \mathrm{S}$ y $70^{\circ} 39^{\prime} \mathrm{W}$, y a $570 \mathrm{~m}$ de altitud media en relación al nivel del mar. Es la capital del país, ubicada en la Región Metropolitana de Santiago, donde residen más de siete millones de habitantes (INE, 2017). Su tipo de clima, según la clasificación de Köppen-Geiger, es Mediterráneo (Csb), con veranos cálidos y secos, e inviernos frescos y lluviosos (Peel, Finlayson, \& McMahon, 2007).

Para comprender el avance espacial del COVID-19 en el territorio santiaguino fueron utilizadas dos variables principales en esta investigación: número de contagios y temperatura superficial (TS). La primera representa la cantidad de personas infectada por el virus, mientras la segunda, que corresponde al calor almacenado en el suelo, permite diferenciar las temperaturas de emisión de la superficie terrestre en los diferentes barrios, algo que no es posible de obtener para la temperaturas del aire, debido a la inexistencia de redes de estaciones y puestos meteorológicos en número y distribución adecuados para dar cuenta de las significativas variaciones espaciotemporales de los climas que se registran al interior de las ciudades. 
La asociación entre las temperaturas de emisión superficial y la temperatura del aire es especialmente estrecha en el llamado nivel de canopia urbana, capa atmosférica cercana al suelo, que no supera la altura de las edificaciones, que recibe directamente la irradiación de las calles, techumbres y fachadas de edificios y viviendas, y que constituye el medio ambiente habitado, donde reside y circula la sociedad.

Trabajos anteriores (Smith \& Romero, 2016; Mendes et al., 2019, entre otros) han indicado que los valores más bajos de temperatura y las menores variaciones térmicas se correlacionan con las más altas coberturas vegetales de los suelos y ambas, a su vez, con la localización de los grupos sociales de mayores niveles socio-económicos.

En cuanto a las tasas de incidencia del virus, se utilizaron datos del Ministerio de Salud chileno, registrados el 08 de abril, 04 de mayo y 26 de julio de 2020, que corresponden también a los días de captación de imágenes satelitales de temperaturas superficiales. Considerando la cantidad de población que reside en cada comuna (INE, 2017), se han determinado las tasas de incidencia, dividendo el número de casos absolutos por la población, multiplicados por 100.000. Las tasas de incidencia son una métrica importante para fines de comparación espacial de los datos, porque consideran no solo la cantidad absoluta de contagiados por municipios, sino que también su relación con la población total, teniendo en cuenta que las áreas más pobladas concentran los contagios.

En lo que respecta a las temperaturas superficiales, se utilizó el satélite Landsat-7 (escena Path: 233; Row: 083), banda 6 (térmica), con tamaño de píxel de $60 \mathrm{~m}$, procesadas mediante el enlace de Earth Explorer (https://earthexplorer.usgs.gov/). Para convertir los niveles de grises (Digital Number - DN) en temperatura superficial se adoptó la metodología de Congedo (2014), considerando el valor medio de los pixeles dentro de los límites de cada comuna. El Landsat-7 tiene un periodo de visita de retorno de 16 días, no siendo siempre posible obtener buenas imágenes en las fechas deseadas, ya que la calidad de éstas depende de que el cielo no esté cubierto por nubes- situación predominante en el otoño e invierno de Santiago-. Por ejemplo, no fue posible investigar las correlaciones en el mes de junio porque las dos imágenes disponibles (02 y 18 de junio de 2020) presentaban más de $90 \%$ de cubierta de nubes.

Las fechas seleccionadas para los registros de temperaturas superficiales corresponden a las más cercanas al registro de contagios y fueron correlacionadas con las tasas de incidencia del COVID-19, considerando las desviaciones estándar de los valores registrados por las imágenes satelitales. Ello debido a que las comunas del sector oriente de la ciudad, por sus usos y coberturas de suelos más vegetados, registran temperaturas más bajas a comienzos del otoño (mes aún cálido), mientras que en el centro del invierno (julio) alcanzan temperaturas superficiales un poco mayores que la media de la ciudad, como consecuencia de que sus mayores superficies verdes y arboladas impiden el enfriamiento excesivo de la superficie terrestre, propio de los suelos desnudos. Por eso, las áreas del oriente de la ciudad mantienen una menor variación térmica y, con ello, una baja desviación estándar en sus valores de temperaturas superficiales (Inostrosa, Palme, \& Barrera, 2016).

\section{Resultados y Discusión}

El avance de la pandemia se ha extendido por toda Latinoamérica. En esta región, Brasil es el país con más cantidad registrada de casos de contagio y muertes, lo que cabría esperar al ser también la más poblada. Sin embargo, Chile, presenta la mayor tasa de incidencia de Latinoamérica (considerando países con al menos $100 \mathrm{mil}$ casos registrados hasta la fecha del 17 de agosto de 2020) y donde al menos el 2,0\% de su población ha sido infectada por el virus. México, Ecuador, Perú y Bolivia, son los países con mayores letalidades, por sobre la media mundial (Tabla 1). 
Tabla 1. Casos absolutos, número de muertes, tasa de incidencia y letalidad por COVID-19 registrados en los países latinoamericanos más críticos el 17 de agosto de 2020.

\begin{tabular}{|c|c|c|c|c|c|c|}
\hline $\begin{array}{l}\text { Lugar en población en el } \\
\text { mundo }\end{array}$ & País & Casos & Muertes & Población & $\begin{array}{c}\text { Tasa de } \\
\text { incidencia }\end{array}$ & Letalidad \\
\hline $6^{\circ}$ & Brasil & 3.359 .570 & 108.536 & 212.559 .417 & $1,6 \%$ & $3,2 \%$ \\
\hline $43^{\circ}$ & Perú & 535.946 & 26.281 & 32.971 .854 & $1,6 \%$ & $4,9 \%$ \\
\hline $10^{\circ}$ & México & 522.162 & 56.757 & 128.932 .753 & $0,4 \%$ & $10,9 \%$ \\
\hline $29^{\circ}$ & Colombia & 468.332 & 15.097 & 50.882 .891 & $0,9 \%$ & $3,2 \%$ \\
\hline $63^{\circ}$ & Chile & 387.502 & 10.513 & 19.116.201 & $2,0 \%$ & $2,7 \%$ \\
\hline $32^{\circ}$ & Argentina & 299.126 & 5.814 & 45.195 .774 & $0,7 \%$ & $1,9 \%$ \\
\hline $67^{\circ}$ & Ecuador & 101.751 & 6.083 & 17.643 .054 & $0,6 \%$ & $6,0 \%$ \\
\hline $80^{\circ}$ & Bolivia & 100.344 & 4.058 & 11.673 .021 & $0,9 \%$ & $4,0 \%$ \\
\hline $235^{\circ}$ & Global & 21.808 .197 & 772.452 & 7.805 .657 .500 & $0,3 \%$ & $3,5 \%$ \\
\hline
\end{tabular}

Fuente: JHU (2020) y Worldometer (2020).

De acuerdo a la Tabla 1, llama la atención que Chile presente la más alta tasa deincidencia de la enfermedad y que al mismo tiempo, junto con Argentina, registre en dicha fecha, uno de los porcentajes menores de letalidad. Las condiciones de vulnerabilidad social relacionadas con los climas urbanos, y los determinantes sociales, están directamente relacionados con el comportamiento espacio-temporal del COVID-19. La ciudad de Santiago está prácticamente dividida respecto a los climas y condiciones socioeconómicas en dos partes: las comunas del nor-oriente y las del poniente y suroriente (Romero, Irarrázaval, Opazo, Salgado, \& Smith, 2010). Las primeras concentran las mejores condiciones de vida y las menores vulnerabilidades en términos de salud, socio-económicas, de vivienda y de condiciones para cumplir cuarentena (Figura 1).

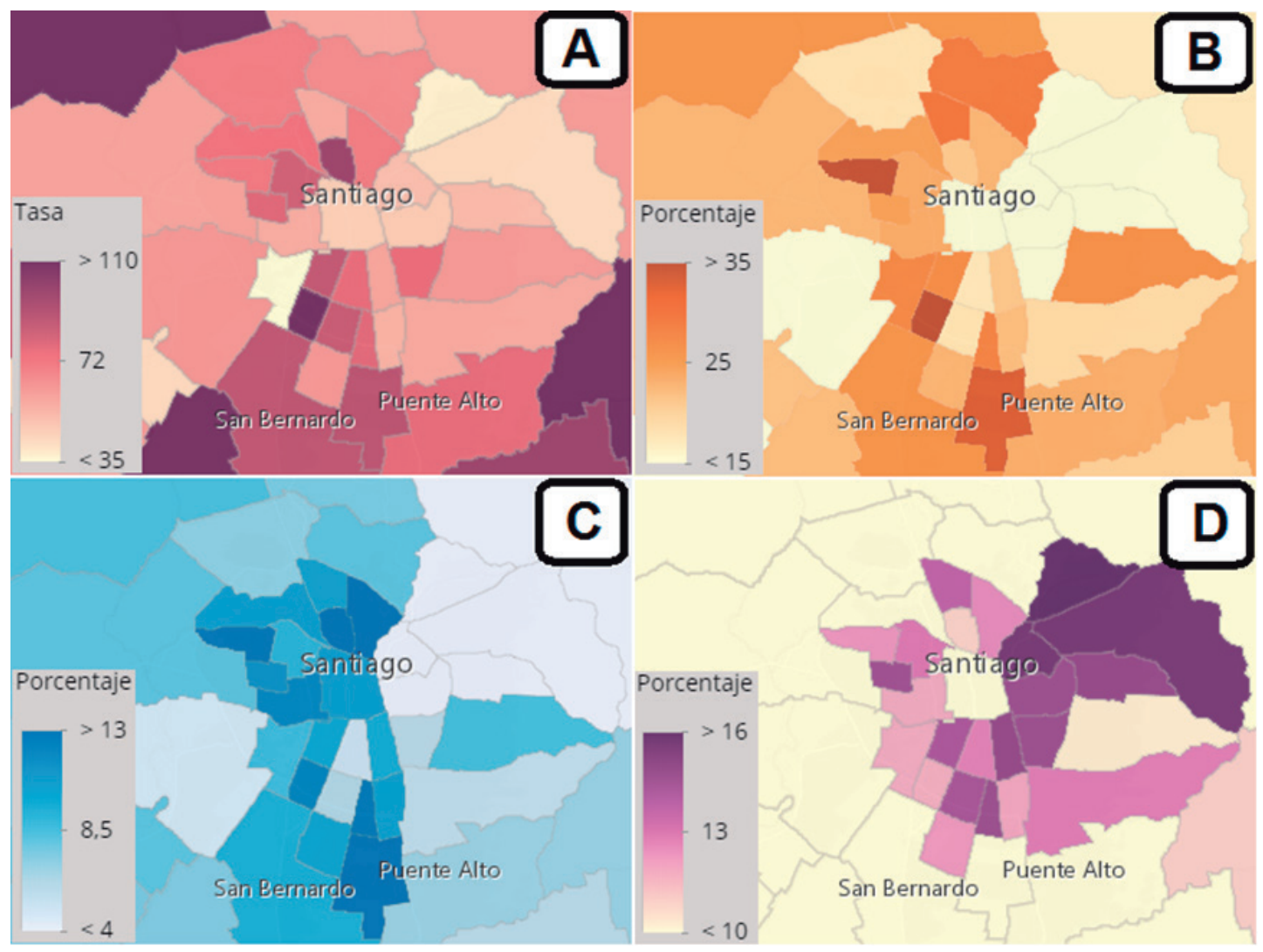

Figura 1. A) vulnerabilidad en salud (mortalidad por causas respiratorias por cada 100 mil hab.); B) vulnerabilidad socio-económica (porcentaje de población en situación de pobreza multidimensional); C) Vulnerabilidad de las viviendas (porcentaje de población viviendo en hacinamiento) y D) vulnerabilidad para cumplir aislamiento en cuarentena (porcentaje de población mayor a 65 años). Fuente: adaptado del Centro de Desarrollo Urbano Sustentable (CEDEUS, 2020). 
Los niveles de diferenciación socio-económica al interior de la ciudad constituyen el principal conjunto de determinantes sobre la calidad de vida y estado de salud de la población de Santiago (Irarrázaval, 2012). La segregación espacial alcanza también a las diferencias socio-ambientales y entre ellas, a los climas urbanos representados por la distribución de las temperaturas superficiales y su influencia sobre las temperaturas del aire. En verano, las temperaturas superan $\operatorname{los} 35^{\circ} \mathrm{C}$, con baja humidad relativa del aire; en invierno, las temperaturas llegan cerca de cero y la sensación térmica puede ser negativa y a través de todo el año es posible diferenciar condiciones de mejor calidad de los climas y del aire en el sector oriente, debido a que las comunas allí localizadas presentan menores densidades residenciales, jardines, gran cantidad de parques urbanos, lagunas y arbolado de las calles. Esta morfología urbana asegura condiciones climático-urbanas más templadas, mejor calidad del aire y por lo tanto, mayor confort climático que cualquier otra parte de la ciudad, garantizando una más elevada calidad de vida y de salud ambiental (Romero, Irarrázaval, Opazo, Salgado, \& Smith, 2010). En términos climáticos significa veranos más frescos, con temperaturas superficiales más amenas e inviernos no tan rigorosos. En la otra parte de la ciudad, el sector poniente (principalmente en el cuadrante 3), el verde urbano es casi inexistente y corresponde a áreas de alta vulnerabilidad socio-climática, con temperaturas de verano más cálidas e inviernos más fríos que el promedio de la ciudad. La Figura 2 presenta la distribución de las temperaturas superficiales registradas en los meses de abril, mayo y julio de 2020 en las diferentes comunas de Santiago.

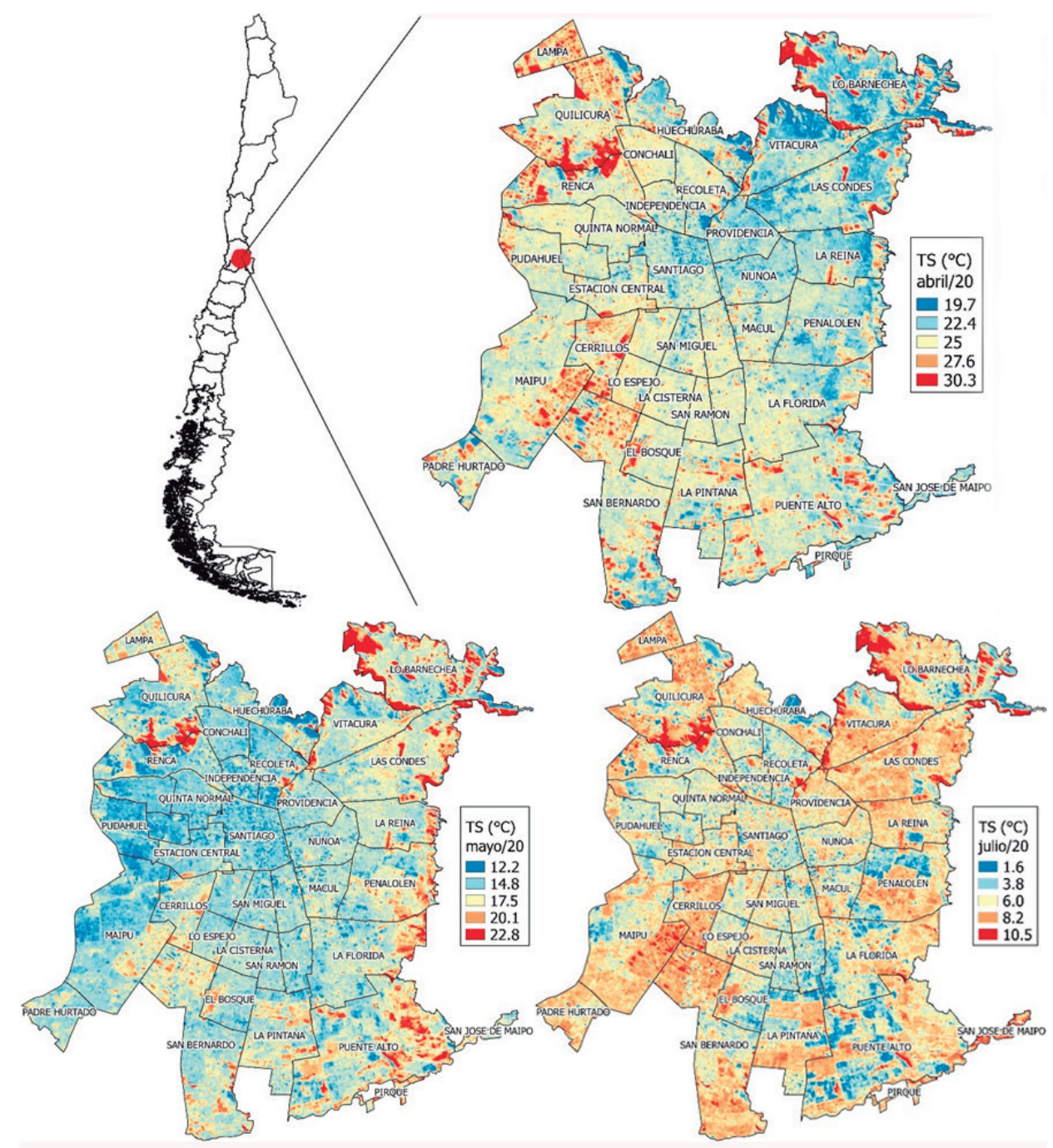

Figura 2. Ubicación de la ciudad de Santiago entre las 16 regiones administrativas de Chile y distribución de las temperaturas superficiales en los meses de abril, mayo y julio de 2020. Fuente: los autores, a partir de imágenes Landsat-7. 
En el mes de abril de 2020 la temperatura media de las 38 comunas de Santiago fue $24,3^{\circ} \mathrm{C}$. Las comunas del oriente (Vitacura, Providencia, Nuñoa, Las Condes, La Reina y Lo Barnechea) registraron valores entre 2 y $3^{\circ} \mathrm{C}$ por debajo de ese valor. Por el contrario, las comunas del poniente, como Lampa, Quilicura y Cerrillos registraron los mayores valores, por ser regiones de alta densidad residencial, sectores industriales y buena parte de sus suelos desnudos o impermeabilizados.

En mayo, cuando se advierte la caída estacional de la temperatura superficial y del aire, al aproximarse la estación de invierno, la media térmica fue de $16,0^{\circ} \mathrm{C}$, y las comunas al oriente - de más elevado nivel socio-económico-, quedaron cerca de este valor, con baja desviación estándar. En julio, en el centro del invierno, la media de la ciudad alcanzó a $5,8^{\circ} \mathrm{C}$, y las comunas del oriente presentaron temperaturas encima de este parámetro, revelando así, su mayor estabilidad térmica. Por el contrario, las comunas del poniente, como La Pintana, San Ramón y Quilicura, marcadas por su gran vulnerabilidad social, registraron los valores de temperatura superficial más fríos, entre cero y $1,0^{\circ} \mathrm{C}$.

Una vez conocidas las diferencias térmicas de cada comuna, se correlacionó la temperatura superficial de cada mes con la tasa de incidencia de COVID-19, en el que el valor de $\mathrm{R}^{2}$ (llamado Coeficiente de Determinación) representa una medida de ajuste del modelo, variando sus valores entre 0 y 1 , es decir, cuanto más cerca de 1 , mayor es la correlación entre las variables analizadas y más explicativo es el modelo (Figura 3). La tasa media de incidencia en las 38 comunas que forman la ciudad de Santiago alcanzaba en el mes de abril a 33 por cada 100 mil hab. En mayo saltó para 184 y, en julio, cerca de cinco meses después de la declaración oficial de pandemia por la OMS, las cifras alcanzaron 3479 por cada 100 mil hab., es decir, afectando a casi el $3,5 \%$ de la población de la ciudad.

En el mes de abril, la relación entre dispersión de las temperaturas y tasas de incidencia era inversa, concentrando el mayor número de contagios en las comunas del oriente, más frescas a fines del verano. En el mes de mayo no se advierte claramente una correlación entre ambas variables, lo que indica una generalización de la distribución de los contagios por toda la ciudad en pleno otoño. En el mes de julio, la relación vuelve a ser inversa entre las mayores tasas de contagio y las áreas de la ciudad con la mayor dispersión de las temperaturas o extremos térmicos registrados esta vez en pleno invierno en forma más marcada en las comunas del sector poniente. Esto significa que los índices de contagio empezaron en comunas de clima urbano más moderado, ubicadas al oriente de la ciudad, como Vitacura, Las Condes, Lo Barnechea y Providencia. En un segundo momento (mayo), se extendieron igualmente por toda la ciudad, mientras que en el mes de julio, fueron las comunas con mayores valores extremos de temperatura las que concentraron espacialmente las mayores tasas de incidencia, como La Granja, La Pintana, San Ramón, Renca y San Joaquín, con al menos 4500 contagios a cada 100 mil hab., correspondiente al 4,5\% de sus poblaciones actuales.

En números absolutos, las comunas de Puente Alto (21.839 casos), ubicada en el suroriente de la ciudad; Santiago Centro (14.329 casos), correspondiente al núcleo más antiguo de la ciudad; Maipú, localizada en el sur poniente (13.848 casos) y La Florida (13.038 casos) localizada en el suroriente fueron las comunas más contagiadas, lo que se correlaciona principalmente con las mayores concentraciones de población, con al menos 400 mil habitantes cada una.

Como se advierte, la distribución espacial del virus presentó una relación directa con las áreas más frías de la ciudad, pero las comunas con menores temperaturas en el otoño, ubicadas al oriente de Santiago, no son las mismas que las que las registran en invierno, ubicadas esta vez en el poniente de la ciudad. Desde el punto de vista de los climas urbanos, las comunas más vulnerables ante el avance del COVID-19 han sido 
las que presentan una mayor desviación estándar de sus temperaturas superficiales, registrando altos valores en los meses cálidos y bajos valores en los meses fríos. Quilicura, La Pintana y San Ramón tuvieron desviaciones estándares mayores que $12^{\circ} \mathrm{C}$, mientras Vitacura, Las Condes y Providencia (juntamente con San José de Maipo y Pirque - comunas más rurales) tuvieron los menores valores, con $8,0^{\circ} \mathrm{C}$. La Figura 4 muestra los cambios en la distribución espacial de los contagios en el tránsito entre las estaciones de otoño e invierno en las distintas comunas de Santiago.
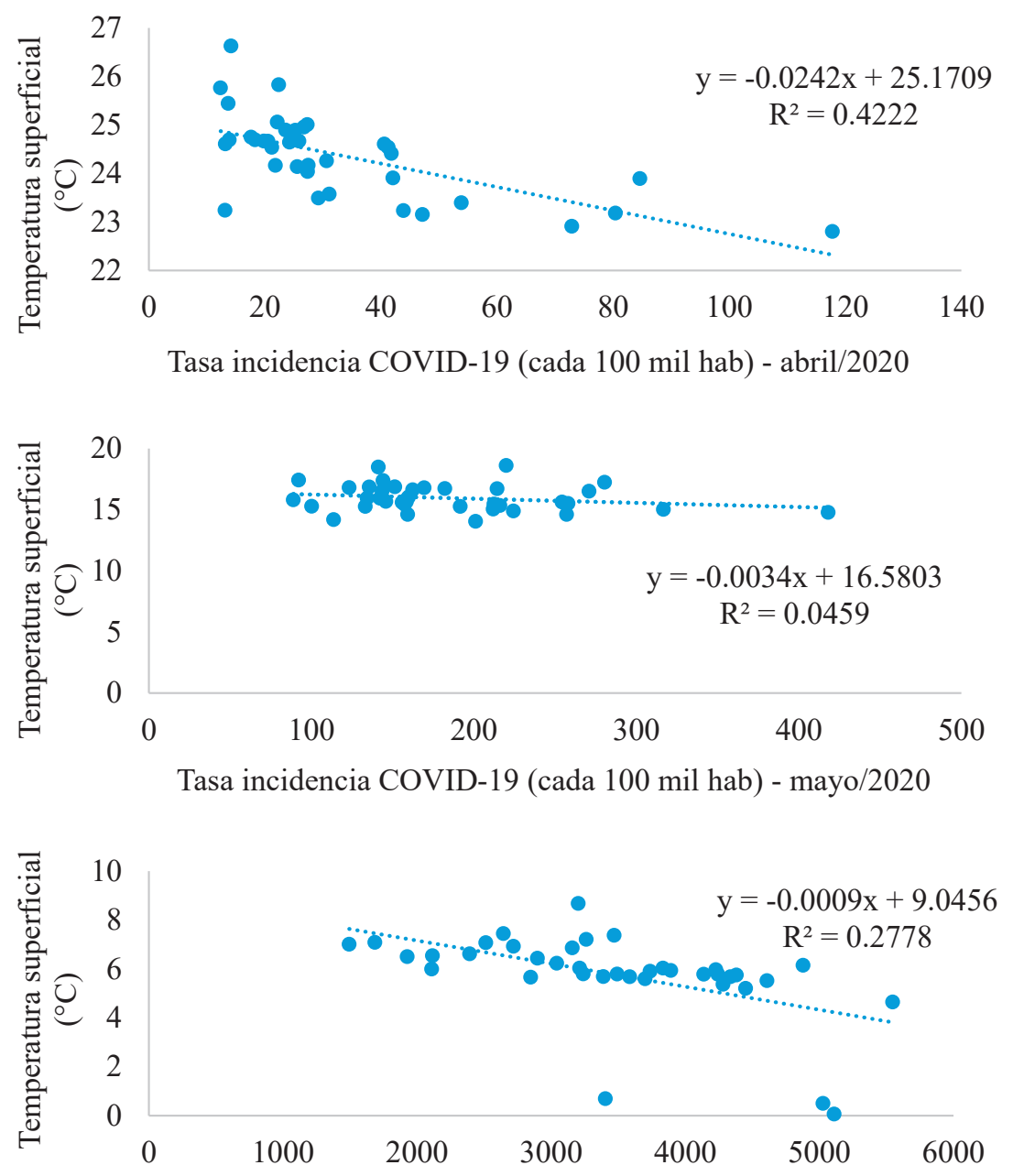

Tasa incidencia COVID-19 (cada 100 mil hab) - julio/2020

Figura 3. Relación entre las temperaturas superficiales y las tasas de incidencia de COVID-19 (por cada 100 mil habitantes) en los meses de abril, mayo y julio de 2020). Fuente: los autores, a partir de datos del Ministerio de Salud.

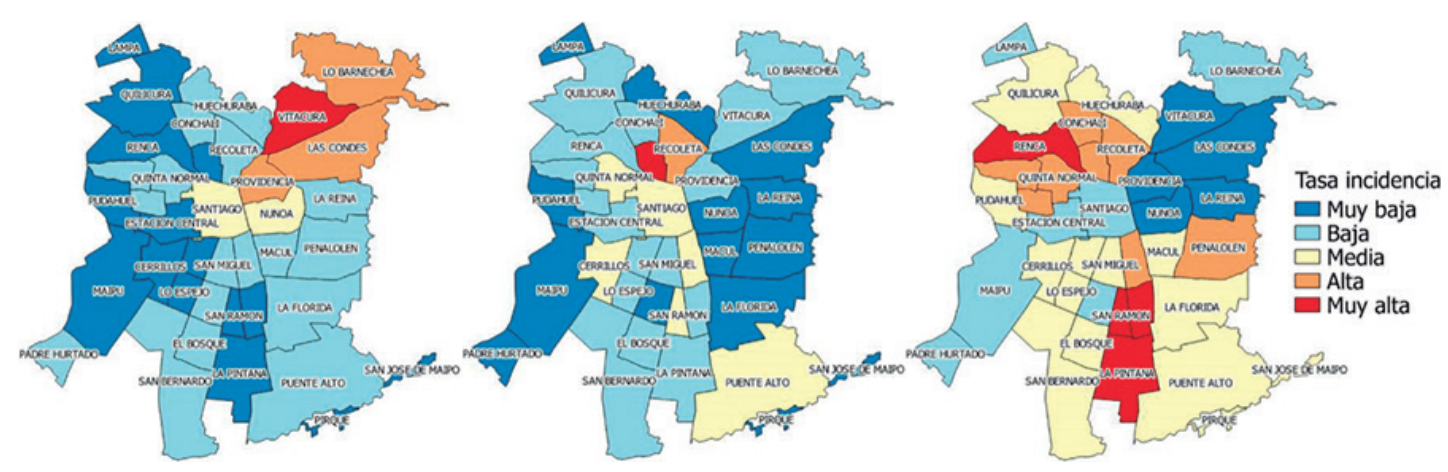

Figura 4. Tasas de incidencia de COVID-19 en los meses de abril, mayo y julio de 2020, respectivamente, a nivel de comuna. Fuente: los autores, a partir de datos del Ministerio de Salud. 
Las diferencias en los rangos de variación de las temperaturas superficiales al interior de la ciudad de Santiago se relacionan con las características de sus medio ambientes urbanos. Las densidades construidas son menores, la impermeabilización de los suelos más baja y la infraestructura verde más abundante en las comunas de mayores ingresos, localizadas al nororiente de la ciudad, todo lo cual mitiga el registro de valores extremos de temperatura superficial en verano e invierno. Por el contrario, las superficies ocupadas con alta densidad de viviendas, predominio de áreas pavimentadas y escasa presencia de áreas verdes, aumentan las temperaturas de verano y disminuyen las de invierno, como sucede en las comunas del poniente de la ciudad.

\section{Conclusión}

La correlación espacial entre las tasas deincidencia del COVID-19 y la distribución de las variaciones térmicas en las diferentes comunas de Santiago presenta diferentes patrones en los meses de otoño e invierno que registraron el mayor avance del virus. Habiéndose originado en las comunas más templadas del oriente de la ciudad, el virus se expandió hacia la totalidad de la urbe en el corazón del otoño, para concentrarse con las mayores tasas de incidencia en pleno invierno en las comunas del sector suroriente y poniente de Santiago, que al mismo tiempo registraban los valores más extremos de temperaturas superficiales. Como los climas urbanos son construcciones socioambientales, el desplazamiento de las tasas de incidencia del COVID-19 se puede interpretar como asociado a las relaciones entre causas climáticas y determinantes socio-económicos, lo que se ha visto corroborado hacia fines del invierno cuando las comunas más ricas del sector oriente fueron también las primeras en mostrar los mejores índices de reducción de las tasas de enfermos junto con el mejoramiento de las condiciones de temperatura. La salud ambiental de los habitantes de Santiago se relaciona espacialmente con componentes importantes del medio ambiente socionatural, tales como los socio-climas urbanos. Solo se pueden mejorar las condiciones de salud ambiental de la mayoría de la sociedad invirtiendo fuertemente en la solución de la segregación socio-ambiental entre sus diferentes comunas.

\section{Agradecimientos}

El presente trabajo fue realizado con apoyo de la Coordinación de Perfeccionamiento de Personal de Nivel Superior -Brasil (CAPES) - Código de Financiamiento 001.

\section{Referencias Bibliográficas}

Centro de Desarrollo Urbano Sustentable (CEDEUS). (2020). Vulnerabilidad Socioambiental a Coronavirus en Chile. Recuperado de https://salud.cedeus.cl/

Congedo, L. (2014). Semi-Automatic Classification Plugin User Manual. Technical Report. DOI: 10.13140/RG.2.1.1219.3524.

Gutiérrez-Hernández, O., \& García, L.V. (2020). ¿Influyen tiempo y clima en la distribución del nuevo coronavirus (SARS CoV-2)? Una revisión desde una perspectiva biogeográfica. Investigaciones Geográficas, 73, 31-55. https://doi.org/10.14198/INGEO2020.GHVG.

Instituto Nacional de Estadísticas do Chile (INE). (2017). Resultados Censo 2017. Recuperado de http://resultados.censo2017.cl/

Johns Hopkins University (JHU). (2020). Coronavirus COVID-19 Global Cases by Center for Systems Science and Engineering. Recuperado de https://gisanddata.maps.arcgis.com/ apps/opsdashboard/index.html\#/bda7594740fd40299423467b48e9ecf6

Inostroza, L., Palme, M., \& Barrera, F. (2016). A heat vulnerability index: spatial patterns of exposure, sensitivity and adaptive capacity for Santiago de Chile. PLoS One, 11(9). doi: 10.1371/journal.pone.0162464. 
Irarrázaval, F. (2012). El imaginario" verde" y el verde urbano como instrumento de consumo inmobiliario: configurando las condiciones ambientales del área metropolitana de Santiago. Revista INVI, 27(75), 73-103.

Ma, Y., Zhao, Y., Liu, J., He, X., Wang, B., Fu, S., Yan, J., Niu, J., Zhou, J., \& Luo, B. (2020). Effects of temperature variation and humidity on the death of COVID-19 in Wuhan, China. Science of The Total Environment, 724. https://doi.org/10.1016/j.scitotenv.2020.138226.

Mendes, F. H., Sousa-Camilo, A.S., Lopes, A. M. S., Polizel, J. L., Silva Filho, D. F., \& Aravena, H. R. (2019). Comportamiento térmico de diferentes superficies urbanas durante un día cálido de verano. Revista Geográfica de Valparaíso, 1(56).

Peel, M. C., Finlayson, B. L., \& McMahon, T. A. (2007). Updated world map of the KöppenGeiger climate classification. Hydrology and Earth System Sciences Discussions, 4(2), 439-473. https://doi.org/10.5194/hess-11-1633-2007.

Romero, H., Irarrázaval, F., Opazo, D., Salgado, M., \& Smith, P. (2010). Climas urbanos y contaminación atmosférica en Santiago de Chile. EURE (Santiago), 36(109), 35-62. http:// dx.doi.org/10.4067/S0250-71612010000300002.

Romero, H. (2019). Urban Climates and the Challenge of Sustainable Development of Chilean Cities. En C. Henríquez y H. Romero (Eds.), Urban Climates in Latin America (pp. 207256). Cham: Springer International Publishing.

Sajadi, M. M., Habibzadeh, P., Vintzileos, A., Shokouhi, S., Miralles-Wilhelm, F., \& Amoroso, A. (2020). Temperature and latitude analysis to predict potential spread and seasonality for COVID-19. SSRN. http://dx.doi.org/10.2139/ssrn.3550308.

Smith, P., \& Romero, H. (2016). Factores explicativos de la distribución espacial de la temperatura del aire de verano en Santiago de Chile. Revista de Geografía Norte Grande, (63), 45-62. http://dx.doi.org/10.4067/S0718-34022016000100004.

Worldometer. (2020). Countries in the world by population (2020). Recuperado de https:// www.worldometers.info/world-population/population-by-country/ 